\title{
Here and now: perceptions of Indian Ocean islanders on the climate change and migration nexus
}

Article

Accepted Version

Kelman, I., Upadhyay, H., Simonelli, A. C., Arnall, A., Mohan, D., Lingaraj, G. J., Nair, S. and Webersik, C. (2017) Here and now: perceptions of Indian Ocean islanders on the climate change and migration nexus. Geografiska Annaler: Series B Human Geography, 99 (3). pp. 284-303. ISSN 1468-0467 doi: https://doi.org/10.1080/04353684.2017.1353888 Available at https://centaur.reading.ac.uk/71648/

It is advisable to refer to the publisher's version if you intend to cite from the work. See Guidance on citing.

To link to this article DOI: http://dx.doi.org/10.1080/04353684.2017.1353888

Publisher: Taylor \& Francis

All outputs in CentAUR are protected by Intellectual Property Rights law, including copyright law. Copyright and IPR is retained by the creators or other copyright holders. Terms and conditions for use of this material are defined in the End User Agreement. 


\section{CentAUR}

Central Archive at the University of Reading

Reading's research outputs online 


\title{
Here and now: Perceptions of Indian Ocean islanders on the climate change and migration nexus
}

\begin{abstract}
Empirical studies exploring the links between climate change and migration are increasing. Often, perceptions are not fully explored from the people most affected by the climate change and migration nexus. This article contributes to filling this gap by eliciting and analyzing perceptions regarding climate change and migration from an understudied population labelled as being amongst those most immediately and directly affected by climate change: Indian Ocean islanders. Open-ended, semi-structured interviews were conducted in two case study communities in Maldives (Kaafu Guraidhoo with 17 interviews and Raa Dhuvafaaru with 18 interviews) and two case study communities in Lakshadweep, India (Kavaratti with 35 interviews and Minicoy with 26 interviews). The results present the interviewees' perceptions of climatic variability and change that they experience; how they perceive the causes of these changes; and links to migration decisions. The interviews demonstrate that perceptions of climate change, of migration, and of the links or lack thereof between the two are centred on the interviewees' own experiences, their own locations, and the immediate timeframe. External information and direction has limited influence. Their perceptions are framed as being the 'here and now' through topophilia (here) and tempophilia (now). The islanders' views do not avoid, but rather encompass, long-term livelihoods and the future. Such a future might be in another location, but the anchor is expressing future hopes and aspirations through the here and now. It is not linked to the wide-scale, long-term issue of climate change.
\end{abstract}

\section{Keywords}


climate change; Lakshadweep; Maldives; migration; perceptions 


\section{Introduction}

The field of environmental migration has a long history exploring influences of environmental changes on human migration patterns over different time scales from sudden volcanic eruptions to long-term climatic trends (Petersen 1958; Munch 1964; Wolpert 1966; El-Hinnawi 1985; Piguet 2012). As contemporary climate change has gained prominence in international research and policy agendas, the interaction between climate change and human migration has garnered increasing attention (Myers 1997; Tacoli 2009; Baldwin 2014a; Brzoska and Frölich 2016). Studies examine the role which migration plays as a climate change adaptation strategy as well as an illustration of inability or failure to adapt (Foresight 2011; Felli and Castree 2012; Palutikof et al. 2013; Withagen 2014); however, not migrating can also be an adaptation strategy or a failure to adapt (Kelman et al. 2015).

Empirical studies are rapidly increasing (Klaiber 2014; Obokata, Veronis, and McLeman 2014) showing how populations deciding or being forced to migrate (or not to migrate) might not always be able to differentiate between climate change related reasons and other environmental reasons (Black, Kniveton, and Schmidt-Verkerk 2013; Baldwin, Methmann, and Rothe 2014; Roberts and Andrei 2015). Consequently, the empirical studies lead to cautions about assuming a clearly delineated and inevitable link from climate change to migration or non-migration (Stal and Warner 2009; Gemenne 2011; Gemenne, Brücker, and Ionesco 2013).

Overall, the truisms from the mobilities literature are being re-articulated in a climate change context that (i) migration and non-migration are two possible responses amongst many to environmental stimuli and (ii) migration and non-migration are part of wider and deeper social and environmental dynamics. To better place climate change and migration literature within wider geographical contexts (e.g. Baldwin 2013, 2014b), understanding local 
perspectives and interests is key to providing empirical evidence for deconstructing the climate change and migration nexus (Featherstone 2013).

To contribute to such work, this article elicits and analyzes perceptions regarding climate change and migration from an understudied population labelled as being most immediately and directly affected by climate change: Indian Ocean islanders. Climate change is taken according to the IPCC's (2014) definition as being any long-term change in climate statistical properties. This article does not explore or validate existing data on climate change or on physical changes affecting the studied islands. Instead, this article presents islanders' perceptions of climate change and migration to determine how they might or might not be considering climate change affecting their future.

The next section reviews scholarly work related to perceptions of climate change and migration, followed by a methods section outlining this paper's empirical contribution from the Indian Ocean case studies of Maldives and Lakshadweep. Maldives has a small amount of previous work on this topic despite long being considered to be amongst the most vulnerable locations to climate change, while Lakshadweep, despite its similarities with Maldives, has not before been investigated for this topic. After the methods section, the results section reviews the interviewees' perceptions of climate change, migration, and the connections or lack thereof between the two topics. Discussion follows, explaining the results in terms of the 'here and now' for livelihoods, leading to theorization of the importance of topophilia and tempophilia for interpreting the climate change and migration nexus. This application of topophilia and particularly tempophilia represents this paper's theoretical contribution, by verifying that these two concepts exist in reality, dominating the islanders' perceptions of climate change and migration. While some prior studies have considered aspects of place attachment, little work so far regarding climate change has examined time attachment and, especially, the combination of place and time. The conclusions indicate that the Indian Ocean 
islanders apparently do not frame their migration and non-migration decisions according to climate change, suggesting a wider scope that external labels of vulnerability to climate change do not necessarily correlate with local perceptions thereof.

\section{Theoretical background}

\section{Climate change and migration}

Much academic discourse on climate change and migration has tended to focus on the expected numbers of migrants, where they are expected to move from and to, and potential consequences. Exploring climate change in wider contexts with respect to population mobility, especially within other reasons for population movement, is explored less (Nicholson 2014; Taylor 2014; Upadhyay et al. 2015). Even when comparatively comprehensive overviews, such as Foresight (2011), tackle some of the why questions based on extensive literature analysis and data collection, others suggest that underlying, long-term drivers of assumptions behind the analyses remain neglected (Felli and Castree 2012).

Previous scholarship has explored the relevance for migration of local perspectives of climate variability and change. Public and government attitudes towards climate change science have been explored in relation to developing more effective responses which include, but are not limited to, migration (McCright and Dunlap 2011; Ruddell et al. 2012; Brownlee, Powell, and Hallo 2013; Held 2016). In many of these cases, the value of alternative views or understandings of climate change tend to be judged according to their proximity to official scientific discourses, rather than taking a deeper, critiquing perspective.

The dominant literature highlights low-lying island communities as being amongst the most vulnerable locations to climate change (IPCC 2014). They have therefore become prominent in debates on climate change and migration (McNamara and Gibson 2009; Gerrard 
and Wannier 2013; Yamamoto and Esteban 2014; Kelman et al. 2015), although empirical evidence for island disappearance under climate change impacts, most notably sea-level rise, is limited thus far (Webb and Kench 2010; Rankey 2011; Ballu et al. 2012; Kench et al. 2016). Climate change impacts other than sea-level rise, such as coral mortality (from elevated sea-surface temperatures and ocean acidification) and reduced freshwater, might precede sea-level rise in forcing major island livelihoods changes (Gerrard and Wannier 2013; Yamamoto and Esteban 2014). As islander voices regarding such changes and potential consequences have increasingly been heard internationally, reactions against the top-down labels of climate 'refugees' and 'victims' are increasing (e.g. McNamara and Gibson 2009).

These island-based studies have made important contributions in grounding perspectives on climate change and migration. Gaps remain in understanding the experiences of low-lying islanders in the Indian Ocean, where Maldives is often represented as a key case study for climate change and migration (Kothari 2014; Arnall and Kothari 2015). The new evidence presented in this article from the Indian Ocean archipelagos of Maldives and Lakshadweep informs the theory of understanding why islander perceptions diverge from dominant, external discourses. It highlights the populations' interpretations of their observations as focusing on local, near-term phenomena, the here and now, rather than considering larger-scale explanations.

\section{Topophilia and tempophilia}

In exploring this article's contributions to the literature, two theoretical concepts are applied: topophilia and tempophilia. Topophilia (Tuan 1974) comes from 'topo' meaning place or local focus and 'philia' meaning tendency, liking, or attraction, thereby being used to mean 'place attachment' or tendency towards the local. Preference for one's own location (namely affinity for the place where one lives) emerges, expressed by characteristics such as quality of 
life, networks, social ties, environmental features, dependence relationships, and integration (Hidalgo 2013; Roca and de Nazaré Oliveira-Roca 2007).

People can remain attached to the place from which they originate or live, covering home, family, livelihoods, identity, culture, language, land, and landscape. The importance of place has been acknowledged and applied for climate change adaptation (e.g. Burley et al. 2007; Agyeman, Devine-Wright, and Prange 2009). Emerging scholarly work emphasizes the need to understand the significance of place identity, place identification, and place attachment when discussing climate change and mobility (Novaczek et al. 2011; Baxter and Armitage 2012; Willox et al. 2012; Graham et al. 2013), although the literature sometimes disagrees on differences and similarities amongst the place-related phrases (e.g. Rollero and De Piccoli 2010). With examples of volcanic eruptions and climate change, Kelman et al. (2015) raise the issue of topophilia to interpret the desire of islanders to stay in or return to their place of origin, even when that place has been or could be devastated by environmental changes.

Using the topophilia or place attachment framing supports previous work from island communities. McNamara (2009) and McNamara and Gibson (2009) show how, with respect to climate change, Pacific island UN ambassadors demand that they be given the power and control to determine how and when they will move, keeping it a choice within their control. Unlike many Pacific islanders-for instance, Rudiak-Gould (2013) examines the Marshall Islands while Tuvalu is covered by, amongst many others, Paton and Fairbairn-Dunlop (2010), Shen and Gemenne (2011), and McCubbin, Smit, and Pearce (2015)-the ambassadors accept that migration will be necessary due to climate change, but they still believe in retaining as much as possible of their country, culture, and identity. While land and place are a significant part of Pacific islander identity and culture (Trask 1991; Curry, Koczberskia, and Connell 2012), the ambassadors recognize the need to move yet 
nonetheless emphasize topophilia for resettlement. Similarly, Rudiak-Gould's (2013) research investigates Marshallese perceptions of climate change and its impacts. He shows significant acceptance amongst the Marshallese of the challenges brought by climate change, yet they understand responses to be domestic and not including migration - ultimately because they wish to stay on their islands because they are home.

Discussion of topophilia leads to a parallel proposal for 'tempophilia', referring to time rather than to place. Tempophilia focuses on what is happening now and what affects people day-to-day; that is, having an affinity for the present time. Ideas of tempophilia have been posited in the literature (e.g. Fabian 2014) and in art (e.g. Pirrwitz and Honnef 2010) but have not yet been fully brought together under a single theoretical banner, as offered by 'tempophilia'. Tempophilia has previously been used to refer to clock-related fetishes while the related word 'chronophilia' appears most frequently in literature regarding age-related sexual preferences. Here, 'tempophilia' is taken to mean having an affinity for the present time, so highlighting and prioritising what is happening now and focusing on immediate interests and needs. This affinity would give credence to present interests and observations over future possibilities imposed from outside the community.

Time has long been studied as part of people's perceptions of changes around them and responses to those changes (Fabian 2014) including for climate change (Slawinski and Bansal 2012; Fincher et al. 2014; Arnall and Kothari 2015). At times, this debate is framed as expert (or elite) understanding of the long-term future under climate change clashing with non-experts (or non-elites) who are so focused on the immediate and the present that they are unable to deal with wider, longer-term topics, such as climate change. Tempophilia, though, tends to embrace rather than preclude future considerations, by (i) recognising that no future exists without meeting day-to-day needs and (ii) addressing multiple timeframes simultaneously, even if the preference is to emphasise or prioritise the present. It is too 
presumptive to indicate that tempophilia means that only a single timeframe can be considered within a mindset or culture.

In fact, the timeframes within which people prefer to focus and how they map out the future for themselves with respect to climate change have had limited exploration, providing a theoretical contribution from this article. Climate change impacts manifest on the decadal timescale, removed from daily concerns until the point at which the changes are so extensive that they impact daily concerns. Glantz (1999) explained this situation as 'creeping environmental changes' in that changes to the environment creep along with limited acknowledgement and reaction until a threshold has been passed creating a crisis, after which action is taken. Tempophilia corroborates the creeping model, because affinity for the present time could make longer-term changes less noticed.

Meanwhile, migration entails leaving a location, with an open question regarding whether or not migrants with topophilia become as attached to their new location as to their old location; that is, how might topophilia be transferred or not amongst locations? Migration does not preclude topophilia, but might undermine, create, and/or re-create it. The theoretical schema thus emerging from this paper is topophilia and tempophilia complementing each other as the framework within which climate change influences on migration could be examined and interpreted.

\section{Method}

\section{Case studies}

In addition to the theoretical contribution, this article provides an empirical contribution, through two archipelago case studies of Maldives and Lakshadweep in the Indian Ocean. Maldives is a sovereign state and Lakshadweep is the smallest Union Territory of India. Both 
archipelagos are part of the same geological structure, their land rises only a few metres above sea level, and they have strong cultural and historic links with each other. Research was carried out in 2013 and 2014.

Maldives, with a total population of 380,000 and a land area of $298 \mathrm{~km}^{2}$, has long faced problems of food insecurity with a reduction in domestic production and affordable imports (Perch-Nielsen Bättig, and Imboden 2008) as part of long-term sustainable development challenges (Ghina 2003). Around the country, nearly $16 \%$ live under the poverty line (Kothari 2014) and almost one-third of the population lives in the capital Male which is close to being 100 percent urbanized yielding a high population density along with difficulties for water run-off and waste management. Maldives has garnered significant attention concerning climate change impacts, particularly regarding consequences from sealevel rise (McGranahan, Balk, and Anderson 2007; IPCC 2014; Kothari 2014; Hirsch 2015). The country's highest point is less than $2.5 \mathrm{~m}$ above sea level with much of the land sitting lower than the expected sea-level rise by 2100 (IPCC 2014), although this statement assumes that the islands are static rather than factoring in geomorphological changes to low-lying atolls which could occur due to sea-level rise (Webb and Kench 2010; Rankey 2011; Kench et al. 2016). A rise in sea surface temperatures under climate change could lead to coral bleaching around the country, as occurred in 1998 (Edwards et al. 2001) which could augment erosion. An additional factor in potential coral mortality under climate change is ocean acidification (Pandolfi 2015).

Alarmed at the potential climate change impacts, the Maldivian government has initiated several national strategies, including the reintroduction of a proposal to consolidate the population dispersed over 200 islands by migrating to $10-15$ islands nearer the capital, albeit with serious social and cultural consequences (Kothari 2014). This policy is not new (Sovacool 2012b), since previously, entire populations were relocated from islands where life 
was not sustainable. In fact, populations from several island communities were resettled following destruction due to the Indian Ocean tsunami of 26 December 2004. One resettlement location is one of the case study islands, Dhuvaafaru. It was selected for resettlement because it was uninhabited and could be developed according to the government's criteria within its 'safer island concept' which also applies to climate change adaptation (Riyaz and Park 2010; Sovacool 2012a).

Following his election as President of Maldives in 2008 ending a thirty-year dictatorship, Mohamed Nasheed made one of his first public pronouncements about the potential for wholesale relocation of the country due to climate change. Nasheed urged that the country might disappear if the current pace of climate change continued to raise sea levels (see also Hirsch 2015), to a large extent conflating climate change impacts with sea-level rise. He stated the need to set up a sovereign wealth fund to buy land for a new homeland, preferring India or Sri Lanka due to similarities in culture and climate while also considering Australia due to the land available. His words intensified discussions not only about the effects of such large-scale migration, but also regarding the rights which citizens would have if their homeland no longer exists and the extent to which international law can deal with such situations (see also Gerrard and Wannier 2013; Yamamoto and Esteban 2014).

Lakshadweep is part of the same geological structure as Maldives and is located 200$400 \mathrm{~km}$ from India's mainland, covering $23 \mathrm{~km}^{2}$ of land area. According to the Government of India $(2011,2013)$, the islands' total population is 64,429 of whom $2.77 \%$ live below the poverty line. The archipelago is one the most densely populated regions in India. Traditional subsistence livelihoods rely on copra and fishing. Tourism is limited, although a tourism development plan is in progress. Lakshadweep has been declared a 'no industry district' to protect its ecosystems. 
As with Maldives, Lakshadweep has long dealt with development- and livelihoodrelated difficulties. Drinking water supply is a major concern, as most groundwater sources have been over-exploited. Lack of proper drainage and waste management continue. Unlike Maldives, potential climate change impacts on Lakshadweep have not been discussed in public fora, on either the islands or the mainland. The focus has been on island economic development.

The majority of Lakshadweep's population is labelled as 'scheduled tribes', referring to indigenous peoples whose status is acknowledged by the Indian government. Gender equality is high and women enjoy a higher social status than elsewhere in India (Government of the Union Territory of Lakshadweep 2015), although the main reasons for migrating within Lakshadweep are employment for men and marriage for women. The Government of Lakshadweep has taken conscious steps to discourage migration from the mainland to the islands, including the need for entry permits for any visit by Indian citizens, even for tourism. As well, the law prohibits people from outside Lakshadweep from buying land within the archipelago and from living there permanently.

In terms of climate change affecting Lakshadweep, the average sea surface temperature around the archipelago has increased by $0.8^{\circ} \mathrm{C}$ from 1911 to 2003 . This rate is higher than the global average of $0.6^{\circ} \mathrm{C}$ (Ahmad 2010) and has affected coral reefs around Lakshadweep (Wilkinson 2008). Sea-level rise could devastate large parts of the archipelago assuming that the islands do not change geomorphologically with the rising ocean. The Lakshadweep Action Plan on Climate Change (LAPCC 2012) has been approved by India's National Steering Committee on Climate Change, but is yet to be implemented.

\section{Interview sites}


Guraidhoo lies in the atoll south of Malé and many of its official residents live and work in the capital. The island sits next to a resort, so many residents from the island work there or run shops and restaurants on Guraidhoo to serve tourists taking day trips. Dhuvafaaru sits about $170 \mathrm{~km}$ north from Malé. Until 2008, Dhuvafaaru was uninhabited, but then the national government chose it as a relocation site for the inhabitants of Kandholhudhoo, approximately 16-18 $\mathrm{km}$ west, the infrastructure of which had been completely destroyed in the 26 December 2004 tsunami. Dhuvafaaru's infrastructure was developed from nothing and building continues there. The primary livelihood is fishing, although some residents work in the atoll's sole resort on another island and they reside in cramped conditions near the resort.

Kavaratti is the capital of Lakshadweep and has a high temporary population where most people move for employment, especially government jobs, and better education. Minicoy shares more ethnographic similarities with Maldives; for instance, food is similar whilst Mahl, the local language, is a dialect of Dhivehi which is spoken in Maldives. Minicoy is an important centre for tuna fishing. The predominance of women in all aspects of life, including the matrilineal mode of inheritance, is particularly noteworthy in Minicoy which is known as the 'island of women' since the majority of men are away working on ships. Migration from the island is linked with aiming for better education opportunities and better health facilities.

\section{Interviews}

Open-ended semi-structured interviews were conducted in four case study communities (Tables 1-3) to examine local perceptions and understandings of changes to the environment around them, their knowledge of climate change, their interests in and abilities for migrating, and the links amongst the environment, migration, and livelihoods. Interviewees were selected in two stages. First, a household survey was conducted through random sampling 
within each location. Then, from those who participated in the household survey, interviewees were selected aiming for gender and age balance along with livelihood diversity. Interviewees also had to be volunteers and Minicoy did not yield as many volunteers proportionally as the other locations whereas, proportionally, many on Guraidhoo were eager to be interviewed. Interviewee ages ranged from teens to septuagenarians while a variety of livelihoods were covered including students, people not formally employed, fishers, politicians, tourism sector workers, and government workers. Only Guraidhoo interviewees achieved a gender balance, with Dhuvafaaru's interviewees being dominated by women and interviewees from both Lakshadweep case studies being dominated by men. Consequently, the results could reflect gender biases as well as portraying few youth perspectives.

Only the interview results, not the household survey results, are reported here. Grounded theory (Glaser and Strauss 1967) was used for the analysis, without preconceived categories, but with the conceptual frameworks emerging from the interviews leading to identification of the key concepts which were clustered into the categories (Birks and Mills 2015; Charmaz 2014) as reported in the Results section.

Insert Tables 1-3.

The interviews were conducted in the local languages, lasted between 30 and 90 minutes each, and were generally focused on one key interviewee in the household (as reported in Tables 2 and 3) but often with other household members sitting in, listening, and contributing. The semi-structured questionnaire used the same template for each location but was slightly modified during local piloting to ensure that locally contextual aspects were covered. Many interviews digressed from the list of questions to ensure that the interviewees' perceptions and understandings were fully captured. 


\section{Results}

The results from the interviews emerged in three principal categories. First, the interviewees' perceptions of the climatic variability and change which they are experiencing. Second, how they perceive the links between these experiences and the causes. Finally, these two perceptions are linked to choices of and perceived reasons for migrating. In reporting quotations from the interviewees, few grammatical corrections are made to their words in order to retain the interviewees' original thoughts.

\section{Perceived climatic and environmental variability and change}

Interviewees in all four locations tended to demonstrate propensity for focussing on immediate and visible impacts with regards to environmental changes in their communities. In Kavaratti, fifteen interviewees mentioned beach erosion as being of immediate concern because it negatively impacts the local jetties interfering with inter-island transport and deliveries of food and fuel. Similarly, ten Kavaratti interviewees and six Minicoy interviewees mentioned that the depletion of fishing stocks is leading to greater local understanding of the link between rising sea surface temperatures and coral bleaching. Interviewee K3 summarized these views: 'If you ask local people about fuel or food subsidy, they would be interested to talk about it, as it affects their daily life, but climate change is not a concern so they do not know and don't understand what TV or newspapers have to say about this'.

Although not related to climate change and not stated as being explicitly or directly linked to climate change, the 2004 tsunami was often referred to during discussions of perceived changes to floods, rainfall, temperature, and storm surges. Interviewee K9 noted changes in temperature and rainfall following the tsunami: 'It is more hot now, rains are 
delayed, in my younger days rains came by May, now they are delayed'. He also described the impact on livelihoods: 'Older people could predict high seas to avoid fishing, now our calculations have failed as things have changed'.

For Maldives, perceptions of changes linked to climate changes varied between the two islands. Interviewees on Guraidhoo reported increased coastal erosion, but those on Dhuvafaaru — originally from other islands - had experienced significant sea flooding in their old communities prior to the 2004 tsunami. Nonetheless, when asked about their experiences of climate-related changes in their lifetime, including sea-level rise, interviewees from both islands spoke only of their personal experiences without considering broader contexts or information sources such as media, friends and relatives in Malé, or the government.

Interviewee G2 said he is 'very concerned about losing his land' while Interviewee G6 mentioned that 'The island had really shrunk. They have lost many, many trees and there used to be a bigger beach area. But now that is gone'. Interviewee G11 explained, 'The shoreline is coming closer, the erosion is really bad now and the water comes onto the island'. Interviewees G9 and G10 remembered changes beginning in the late 1970's. They recounted that the sea level has been rising, as witnessed through higher tides, the destruction of trees, and storm surges coming much further inland. The Island President (Interviewee G14) said that locals tended to take rocks and debris from destroyed properties to rebuild their homes and coastlines.

The Dhuvafaaru interviewees perceived that they had experienced significant sealevel rise prior to the tsunami on their previous island, Kandholhudhoo, and that they could see such 'evidence'. On Dhuvafaaru, almost every interviewee (seventeen out of eighteen, including the younger ones) could point to specific climatic changes seen in their lifetimes, identifying pre-tsunami increased air temperatures and rising seas. They used the tsunami as a reference point, but they were not equating climatic changes to the tsunami. Interviewee 
D10 was the only exception, but he kept the discussion strictly on post-tsunami island redevelopment and migration, not wishing to discuss his personal pre-tsunami or tsunami experience in detail.

\section{Perceived attribution and impacts of observed climatic variability and change}

Discussion of 'sinking islands' due to sea-level rise was familiar to interviewees from Kavaratti and Minicoy. All interviewees in Kavaratti and fifteen interviewees in Minicoy mentioned it as emerging from visual and print media, yet they do not identify with these concerns due to what they perceive as being alarmist claims without evidence. To them, 'evidence' is stated as being self-observation and experience in their immediate surroundings. Interviewee K16 said that 'No sinking has ever happened, so how can we say what we will do and if there was a concern regarding sea-level rise - there would be community discussion about it'. Meanwhile, Interviewee K18 noted, 'I have heard that Maldives will sink by so and so date but it is still there'.

The lack of attribution of witnessed changes to contemporary climate change was definitively linked to lack of direct experience. As Interviewee K14 described, 'Local people cannot imagine what a glacier or iceberg is and that it is melting due to climate change and causing sea levels to rise'. The attitude of the Lakshadweep interviewees overall was not that the islanders are climate change sceptics or that they are short-sighted and parochial. Instead, they explain that they prioritize what they experience and they are most interested in their present-day livelihoods challenges. They cannot conceive of climate change simultaneously impacting all the islands in similar ways because changes are seen as being local. For example, Interviewee M3 explained, 'Every island in Lakshadweep is maturing and growing in land mass, therefore the concept of sea level [rise] is very opposite to what people observe 
and see'. Similarly, five interviewees in Kavaratti (K3, K5, K9, K15 and K20) associated rising temperatures with increased concretization on the island.

Meanwhile, all interviewees in Kavaratti and twenty in Minicoy talked about responding to changes in rainfall patterns, noting irregularity and increases in heavy precipitation while indicating that reactions to any kind of risk or disaster-such as floods, epidemics, or wars - are often explained in religious terms rooted in teachings of the madrasa or mosque. In the context of climate change, many people believe 'Climatic changes are acts of god and, if they happen, he will take care of them' (Interviewee K11) or 'If we get washed away then god will come to save us' (Interviewee K7). Similarly, Interviewee K9, citing his distrust of television weather forecasts, voiced, 'If people will go against religion, then nature will come back to punish them'. In Minicoy, Interviewee M5, who was unaware of global climate change or sea-level rise, also attributed any disaster to god's punishment. These explanations and meanings indicate a belief that only god has the power to influence the climate and its effects.

For Maldives, no interviewees brought up 'sinking islands', used that vocabulary, or alluded to it. Eleven interviewees on Guraidhoo and eleven interviewees on Dhuvafaaru had some level of awareness about climate change, hearing about it from either television or radio. Interviewee G7 discussed climate change as attributed to 'pollution, not unlike the ozone layer' yet considered climate change to be a future, rather than present, concern. The Maldivian interviewees focused on immediate, visible causes and impacts leading to associations with everyday experience and what makes sense for everyday life, namely religion and the 2004 tsunami. Yet despite other Maldivians mentioning religion, Interviewee G5 was the only Maldivian mentioning god directly. When asked about climate change, he replied, 'Humans have nothing to do with it, the superior power is making it happen...if the sea rises fast again, like the tsunami, we will not survive'. 
In Maldives, Interviewee G4 described that the impact of climate change '... will be huge, like the tsunami'. Interviewee G5 believed that climate change was a process started by god: 'If the sea level rises fast like the tsunami, they will not survive'. The Maldivian interviewees reported impacts of property destruction, loss of all the trees, and high waves often entering their homes. Ten interviewees had experienced water in their homes and property damage. Interviewee D1 remembers the tides getting higher over time, eventually scaring her. The former Island Chief (Interviewee D13) explained that the east and west sides of their old island began to flood consistently during both monsoons. Interviewee D5 stated that she lost her television and some furniture due to waves while Interviewee D14 had similar experiences, losing his refrigerator and other household items and overwhelming his ability to handle the situation. He recalls, 'The waves got so high that the water in the house was above my knees. I was bailing out buckets of water and fainted. I was taken to the hospital'. Interviewee D6 remembers water getting into her home while she attended first grade as a child. Irrespective, all eighteen interviewees said that fishing, which is their livelihood basis, was good despite the flooding and those who had lost belongings had no problems replacing them.

\section{Perceived links to migration}

Interviewees were asked about their interests in and perceptions of migration. Few interviewees in Lakshadweep indicated that they feel they should consider moving due to climate change. Migration was suggested as a temporary measure, mainly for education and jobs. Six Kavaratti interviewees (K7, K9, K11, K14, K16, K20) mentioned governmentsupported relocation as a last resort, to be enacted only if survival would no longer be possible on their island. Interviewee K10 said 'I will decide as per the situation'. The association with their place of origin is strong and many residents of Kavaratti who had 
moved to the mainland for education or employment then returned, as they miss the island lifestyle and community bonding. Interviewee K5 noted that 'People who are born and brought up here don't like it anywhere else. I moved for seven months but quit my job in the mainland and came back because here I have peace of mind'.

In Minicoy, men have traditionally moved away from the island to work on ships, or they have joined the Indian merchant navy, but their home remains as Lakshadweep. Interviewees M2 and M26 who had migrated for employment, and M6 who had migrated for education, discussed their strong willingness to move back to Lakshadweep after a period of time away from their home islands. M26 expressed, 'Though I can live in the mainland comfortably, I am eager to return to my island as I am not homesick but island sick; I even miss the casual clothes that we can wear on our island', focusing on the day-to-day culture of their home. Interviewees M6 and M20 commented, 'Migration may become necessary if sea levels rise as predicted, however we are not happy to move out of our island'.

Sentiments were community-orientated, about what they enjoyed in their present location at the present time, focused on staying on the islands. Interviewee K9 expressed, 'We want to live in our own land, our home and where our forefathers have lived. All my ancestors are buried in this land'. Others commented, 'This is my motherland, it's relaxed here, and I won't leave' (Interviewee K18); 'This is my birthplace' (Interviewee K32); 'I want to live here only' (Interviewee K24); and 'We can't live this happily anywhere else' (Interviewee K9). Not even a disaster would move Interviewee M5, who explained how 'Those who believe in god need not think about disaster or moving because of it, because god will save them'.

In the Maldivian communities, youth go to Malé if they aspire to a college education and few return to their islands of origin to stay. Interviewee G14, the Island President, returned. He did not care for the 'concrete jungle' of Malé and also wished to return in order 
to give back to his people. This sentiment was echoed by youth on Guraidhoo. Interviewees G1, G2, and G3 - young men aged between 19 and 22-agreed that they would not want to leave home, with the eldest $(\mathrm{G} 2)$ commenting 'It is the best place to live'. When questioned about the possibility of migrating due to sea-level rise, they gave a variety of reasons for not wanting to move based in notions of home, place, and identity — what they had and enjoyed in their community at the moment. The rest of the Guraidhoo interviewees acknowledged that they may have to move due to climate change.

Yet a main driver of the desire to migrate out of Guraidhoo is lack of space. Every available land plot is owned, so young couples and growing families cannot have their own homes and must stay crowded with relatives. Interviewee G6 explains that she was in a lottery to win a plot on the newly redeveloped Hulhulmalé island, beside Malé, since she currently lives with her parents in their home with her husband, six children, and two grandchildren. She is interested in moving to where she could have better access to more services such as health and education. Plans to double Guiraidhoo's size through reclamation are meant to address this concern in theory. In practice, no formal timeframe exists for starting the reclamation.

Conversely, in Dhuvafaaru all interviewees were happy with their new community, so they felt no drive to move again. The only complaint levelled against the rebuild was that the new island was too large, with D11 saying that she was sad because she 'lives far from family and friends now'. Nevertheless, all Dhuvafaaru's interviewees indicated that they may have to move due to sea-level rise. While they would prefer to stay, they were reasonably amenable to migration, considering that they had already been relocated once, post-tsunami. Ten Dhuvafaaru interviewees preferred to move as a whole island community. Interviewee D14 explains, 'The community is good, it is strong, and that is why they should all move and stay together. We don't want to separate'. 
If they needed to leave again, for example due to climate change, eleven Dhuvafaaru interviewees preferred to migrate within Maldives, going to Malé or Hulhulmalé. They expressed sentiments similar to Interviewee D12 that 'It's safer there' than other countries. For the ten Maldivian interviewees who suggested interest in moving to places outside of Maldives, they much preferred another country perceived to have similar culture and religious values, suggesting Saudi Arabia, India, and Sri Lanka. Interviewee D1 suggested Macau and Interviewee G8 suggested London or Paris.

In summary, the impetus of all the islanders interviewed was to stay as close to home as feasible because it is home and is the preferred abode. Migration is occasionally considered or discussed due to climate change, but migration is much more relevant for education, employment, health, and livelihoods - themes which matter immediately to people for their day-to-day lives in order to build a better life for the future. This better life would preferably be on their home island or, for most Guraidhoo interviewees, staying in their home country of Maldives.

\section{Discussion}

The results demonstrate that the interviewees' perceptions of climate change, of migration, and of the links or lack thereof between the two are centred on their own experiences, their own locations, and immediate timeframes. The interviewees understand and express migration largely via the contexts of personal change and personal experience; what affects them in their home at the present time, although nonetheless linked to a better future. For them, migration as a response to the climate changes that they are witnessing, or that they hear could come in the future, was not a priority. Connecting climate change and migration is not a personal experience they have lived through and hence is outside their possible 
framings. These perceptions are framed here as being the here and now through topophilia (here) and tempophilia (now).

\section{Topophilia}

The interviewees from Maldives and Lakshadweep displayed topophilia, identifying themselves as islanders and expressing a strong sense of place identity. Migration was not considered to be a priority because people felt at home and they like their home, irrespective of any potential or observed climate change impacts. Where migration is considered, it will be a choice — for education, jobs, and family—not forced by external pressures such as the changing climate. The possibility to return home to their island was always assumed to remain. As such, people's options are not reduced to a form of climate change determinism in which the climate's agency dominates the people's agency.

The work here advances these topophilia discussions which are starting to be expressed in climate change literature by demonstrating the clear views from the interviewees that being islanders comes first. Even in the context of climate change and migration, place remains paramount for identity. This contrasts with politicians' and policymakers' views which tend to project changes taking place in Maldives to a more abstract and global level of significance (cf. Hirsch 2015). The results here from all four communities indicate that any attempts at discussing migration related to climate change would need to be conducted in the context of topophilia, in that the islanders would rather stay in their current homes and might not consider moving until they are physically forced-which occurred with Dhuvafaaru. The importance of topophilia as a theoretical framing has not yet been so starkly identified based on empirical data for island communities.

In comparing the literature and results from Maldives with the results from Lakshadweep, topophilia might further represent more than place as location. Instead, it also 
encompasses what happens in that location: community, identity, traditions, and ways of life - as eloquently articulated in many of the interviewees' quotations and in the island studies literature (e.g. Baldacchino 2008). Sense of place for island communities, by definition, also encompasses the water surrounding and between the land (Hau'ofa 1994) with recent topophilic explorations defining these spaces as 'aquapelagos' (Hayward 2012). Perhaps the islander connection to the water, espoused in such literature and in the interviews here, makes climate change impacts including sea-level rise possibilities appear to be less fearsome, since water is part of the community, identity, and placeness of island topophilia.

Conversely, migration might entail moving away from the aquatic places and losing the intense land-water relationship inevitable in the island communities studied here. This dislocation has led to loss of identity and topophilia for island populations (e.g. Steel 1975 for St. Kilda, Scotland) with this possibility perhaps seeming to be far more tragic to the islanders than remaining in their communities and, in their homes and in their place, dealing with whatever climate change brings.

\section{Tempophilia}

The results from Maldives and Lakshadweep display similar temporal views to each other, with the interviewees focused on the present. The interviewees see changes to their environment happening at the moment and which need to be addressed now. Some of these changes are quick such as the tsunami and some are longer-term such as beach erosion. The islanders do not attribute those changes to climate change and they do not project these changes into the future. Irrespective of the speed of the changes, the islanders' temporal view is focused on what they can observe and respond to now, rather than necessarily reasoning that slower changes could be dealt with later. The interviews do not provide evidence for 
considering action later for slow-onset changes, instead focusing on what is observed at present and could be dealt with.

Furthermore, the interviewees' temporal basis for perceiving climate change and migration is focused not only on what they experience immediately, but also on aspects over which they have some control, such as migrating for education and jobs; that is, aspirations and concerns of day-to-day life for a better future (see also Fabian 2014). Dimensions outside their control - such as forced migration, the possibility of eventual inundation from the sea, and changing patterns of weather or fisheries over the long-term-are much less relevant precisely because these changes are longer-term and, from their perspective, less controllable.

In considering how the interviewees view time in the context of the climate change and migration nexus, the observations here match existing work to a large degree (Brace and Geoghegan 2011; Doyle 2013; Arnall and Kothari 2015). One common theme from the interviewees was that the environmental changes they observe are localized, hence the focus on local space and place described in the previous section as well as highlighting what the islanders themselves have the possibility of changing. Another common theme was that the sense of urgency and the future crisis indicated by elites, in Arnall and Kothari's (2015) framing, is not repeated by the Maldivians or Lakshadweepers.

The interviewees' focus on the current time, i.e. tempophilia, contrasts with climate change discourses and images which are often presented as being the present-day threat to island communities from rising sea levels (Farbotko and Lazrus 2012; Arnall and Kothari 2015). Consequently, both views are tempophilic. The construction of a present-day threat focuses on the current time through alarming prognostications which might be accurate, but which provide little evidence from local, day-to-day observations or from past experiences. The islanders, simultaneously, focus on these local, day-to-day observations to determine what to be concerned about and what to respond to. 
In Maldives, the top-down view of a current threat and a major climate change crisis to be dealt with now has been constructed (Hirsch 2015), including by Nasheed when he was President. He held an underwater cabinet meeting to highlight sea-level rise, talked of starting a fund from tourism income to purchase land to which Maldivians could move, and claimed that the country was too poor to attend the Copenhagen climate change negotiations in 2009. This message of climate catastrophe emanating from those with power, backed up by an international scientific view that climate change is a present and major crisis, differs from the perceptions of the more gradual, incremental, localized nature of change experienced by the interviewees (see also Gaillard 2012; Arnall and Kothari 2015; Kelman et al. 2015).

In comparing elite and non-elite perceptions of climate change and migration in Maldives, Arnall and Kothari's (2015) article shows how 'elites focus on a distant future which is generally abstracted from people's lives' (p. 202) while simultaneously creating 'a sense of impending crisis by invoking a policy discourse of immediacy and urgency' ( $\mathrm{p}$. 201), so specifically non-distant and non-abstracted. Thus, in Arnall and Kothari's (2015) study, both the future and tempophilia have been invoked by elites to instil a need for immediate islander action on climate change. Meanwhile, many scientists and politicians, particularly in an island context, also express that climate change is here and now, appealing to tempophilia. For instance, Veron et al. (2009) describe ongoing coral bleaching due to climate change devastating reefs while Wright et al. (2014) explain how crop productivity is now suffering major consequences due to climate change.

Anote Tong, when he was President of Kiribati from 2003 to 2016, became known for speaking about climate change as a present crisis. He hosted the 10 November 2010 Tarawa Climate Change Conference leading to the Ambo Declaration which in clause 1 declares 'Alarm at the impacts of the climate change crisis already being felt in our countries threatening the sustainable development and security of our countries, especially the 
immediate threat to the livelihood and survival of the most vulnerable States'. Tempophilia is invoked through alarming warnings. Similarly, Melillo, Richmond, and Yohe $(2014,1)$ open with 'Climate change, once considered an issue for a distant future, has moved firmly into the present'. Consequently, the elite view from political and scientific realms is that climate change is not just a future or distant crisis, but is also a current one, to which islanders and the world must respond now.

Interpreting the results here through tempophilia assists in understanding the divergence between the islanders not being concerned about climate change and external views of climate change as an urgent crisis for the islands. Perhaps the artificiality of the external discourses to many of the interviewees explains why Nasheed's crisis talk, alongside Maldives as an international poster-child of climate change, has had little impact on Lakshadweepers' views, despite the geographic, cultural, and physical geography similarities between the two archipelagos. These similarities, perhaps, lead to comparable tempophilic views.

\section{Using the here and now to construct futures}

The evidence from the interviews is that people's concerns with respect to climate change and migration are about the here (referring to local space and their place for home, namely topophilia) and now (referring to short-term time scales and what people witness immediately, namely tempophilia). It remains an open question regarding how parallel the two theoretical notions are as well as an open question regarding the origins of these views, given the topophilic and tempophilic expressions in the interviews. Certainly, past experience and amiability towards current living conditions play a strong role in grounding views and expectations in the here and now. Yet neither obviate ambition in seeking an improved future, especially for the next generations. 
In fact, rather than ignoring or being fearful of the future, the 'here and now' approach from the islanders encompasses long-term livelihoods and the future for children and grandchildren, including a potential future in other locations. The anchor for expressing interests and ideals nonetheless remains as the here and now, focusing on personal experience and personal interests within which to frame the future and its possibilities. The evidence and discussion match remarkably well with the island utopia described by Huxley (1962), the cultural focus of which is the here and now in order to retain their idyll for the future without considering what is happening in the world outside of their island.

The focus on current, personal experience explains why, when asked about sea-level rise (which is expected to be a major climate change impact affecting the islands studied here), the interviewees tended to mention only what they have personally experienced and witnessed, such as beach erosion in Lakshadweep and the 2004 tsunami in Maldives. It seemed that such changes might entail migration, as the tsunami did in terms of resettling people on Dhuvaafaru, but it should not be a problem to migrate to another island. Little notion existed that the causes of the beach erosion, the tsunami, or sea-level rise could affect other islands, possibly all other islands in their archipelago, too. Instead, observations were about the current location at the moment, so the islanders' view is that migration elsewhere should be able to avoid similar phenomena. The interviewees are not ignoring or avoiding the future under climate change, most notably sea-level rise. Instead, they are planning for a future which matches with their current, personal experience.

The lack of influence of external information corroborates the here and now. In Lakshadweep, despite regular environmental change awareness programs, the influence on the interviewees of external information sources was limited. The interviewees' future focus is on home, community, and maintaining identity —in effect, retaining what the people have in the place where they live now (topophilia and tempophilia). In Maldives, international 
media and journal headlines have long portrayed apparent climate change risks, typically focusing on assumptions about the implications of sea-level rise, yet the interviewees' responses referred to their daily experiences. Again, this situation corroborates a focus on what the people have in the place in which they live now (topophilia and tempophilia).

The analysis here matches the broader risk management literature which widely acknowledges that most people, in the first instance, tend to respond to risks that they perceive to be immediate and directly personal in their current location (Paton 2001; Moser and Dilling 2004). This attitude is not attributed to poorer, less developed, or more faithbased people, because it tends to be common across many sectors, locations, and risk topics, notwithstanding multiple nuances, subtleties, and contextualities raised in each study. The people's perceptions do not inevitably stem from apathy, fatalism, ignorance, or stupidity, but are about using the past and present to frame, envisage, and plan for a future which is hopefully better, especially for one's children and grandchildren, in the same or similar location. Nor is it necessarily a case of fear of the unknown, clinging to the present location at the present time due to anxiety about what they have never experienced. In fact, none of the interviewees indicated that they might be scared to move or dismayed at what they might encounter in other locations. Rather, it simply was not desired and was not a consideration due to the importance of the here and now alongside the expectation that any changes would still yield congruence with the current situation. Consequently, migration is in the picture of possible futures, since it has been a strategy long adopted for education, livelihoods, health, family, and adventure - that is, for a better future (e.g. Böcker et al. 1998; Portes and DeWind 2007; Foresight 2011; Felli and Castree 2012)_but not in a location radically different from the here and now.

\section{Conclusions}


Climate change presents huge challenges, including its potential influences on migration and non-migration. This study shows that not everyone- even in those communities deemed to be highly vulnerable-perceives or understands climate change to be an important consideration for migration and non-migration. The lack of interest at the community level, as shown by the data from Maldives and Lakshadweep, can appear to outsiders as being ignorant, uncaring, or lazy. In contrast, it is based on sound livelihoods principles within clear spatial and temporal framings which are separate from top-down articulations of climate change and its impacts. Climate change expectations and consequences can be removed from people's everyday lived realities and interests, now and for their future.

No previous studies were found for Lakshadweep of local perceptions regarding migration, environment, or livelihoods topics. As such, this article extends the cohort of lowlying islands appearing in the literature regarding climate change and migration perceptions. This study challenges much of the orthodoxy on people's perceptions of climate change and migration links. Previous studies for Maldives are few (e.g. Kothari 2014; Arnall and Kothari 2015; Hirsch 2015) and also indicate a disconnect in terms of outsider perceptions of local views and interests, compared to the self-contained logic which the islanders' perceptions provide.

This empirical contribution is useful because the form and extent of the relationship between different forms of mobility/non-mobility and climate change continues to be debated across multiple dimensions (Hartmann 2010; Felli and Castree 2012; Bettini 2013; Nicholson 2014). The dominant narratives tend to emerge from top-down interpretations which become accepted and privileged because they are stated by elites (Arnall and Kothari 2015). Yet these narratives and forms of knowledge impact livelihoods and decisions of everyone connected to the island communities, including the islanders' national governments and diasporas. The evidence and theorization from this article demonstrate the importance of the multiple views, 
especially to ensure that local visions of the future are not discounted in policy debates because the people's perceptions are rooted in the here and now which, to some, can seem to invalidate these local perspectives.

This empirical contribution has also tested this article's theoretical contribution through applying the comparatively new notion of tempophilia to a case study while investigating its complementarity with the well-studied concept of topophilia. Yet for climate change and migration studies, even topophilia is understudied and, at times, the work seems to connote that migration should be problematized. In contrast, this paper shows that topophilia is not necessarily to be seen in opposition to migration, just as tempophilia does not contradict caring about and planning for the future. From Huxley's (1962) 'here and now', topophilic and tempophilic framings do not preclude considering other places and other times. Neither climate change nor potential migration links are ignored, but they are not as relevant or interesting as day-to-day life at home.

If the islanders continue to display little interest in climate change, yet physical science and social science publications state that their homes and communities could be wrecked by climate change impacts over the coming decades-including but not limited to sea-level rise-then how could the different knowledges be reconciled? Should policy makers adopt the right, responsibility, or duty to try to convince the islanders to take climate change and migration more seriously, on the terms of the external parties? Or should the islanders' preferences be accepted by policy makers? If topophilia and tempophilia explain the lack of engagement with climate change, and hence the lack of consideration of climate change with respect to migration and non-migration decisions, then should policy makers implement projects in which they enter communities and actively work to change this situation? Or could such a proactive, directed policy stance cause more problems than it 
solves, especially by devaluing local perceptions which many researchers and practitioners explain are important?

These questions interweave ethical and operational considerations which the literature often sidesteps, sometimes not even asking them. Until recently, much research on climate change and migration made assumptions about the importance of climate change for migration, typically framing the topic as climate change having linear causality for forced migration so it is important for the people affected to understand the possible migration consequences of climate change (Nicholson 2014). Soliciting views directly from the people potentially affected on their own terms, and applying the theoretical constructs of topophilia and tempophilia together, provides two main implications for future research.

First, it exemplifies the complex interactions amongst climate change, migration, and other factors suggesting that research could do more to analyse and map out the relationships and lack thereof, particularly according to community-based perspectives. This point leads to the second implication of listening to the framings which people potentially affected by climate change provide, rather than imposing external framings - such as of vulnerability, resilience, climate migration, and climate (change) refugees-onto them. This approach is not adjudicating 'right' or 'wrong' to different views, but is respecting how people perceive and interact with changes in their society and environment, incorporating those perceptions and interactions into policy recommendations.

To the islanders, their future is about home and community based on what they have now. Their decision framing sits within this scope, the here and now, rather than connecting with wider-scale scenarios and projections. Recognizing this situation provides a useful starting point for continued research into the influence of topophilia and tempophilia on perceptions and understandings of the climate change and migration nexus. With this baseline, research can indicate how policies and actions could use topophilia and tempophilia 
for islanders making their own futures-related decisions on their own terms, integrating the two concepts into participatory development processes dealing with climate change, its impacts, migration, and non-migration amongst other topics. Although local perceptions do not highlight climate change or its impacts in the case studies examined here, the islanders are not avoiding the future. They are framing it in different ways, expressed as hopes and aspirations from the here and now long into the future as constructed on their terms.

\section{Word count}

Not including tables or references: 9,281

\section{References}

Agyeman, J., P. Devine-Wright, and J. Prange. 2009. "Close to the Edge, Down by the River? Joining up Managed Retreat and Place Attachment in a Climate Changed World." Environment and Planning A 41: 509-513.

Ahmad, S. M. 2010. "Impact of Climate Change on Hard Corals of Lakshadweep Islands." Paper presented at the National Climate Research Conference, Delhi, March 5-6.

Arnall, A. and U. Kothari. 2015. "Challenging Climate Change and Migration Discourse: Different Understandings of Timescale and Temporality in the Maldives." Global Environmental Change 31: 199-206.

Baldacchino, G. 2008. "Studying Islands: On Whose Terms? Some Epistemological and Methodological Challenges to the Pursuit of Island Studies." Island Studies Journal 3: $37-56$.

Baldwin, W. A. 2013. "Racialisation and the Figure of the Climate-Change Migrant." Environment and Planning A 45: 1474-1490. 
Baldwin, W. A. 2014a. "Pluralising Climate Change and Migration: An Argument in Favour of Open Futures.” Geography Compass 8: 516-528.

Baldwin, W. A. 2014b. "The Political Theologies of Climate Change-Induced Migration." Critical Studies on Security 2: 210-222.

Baldwin, W. A., C. Methmann, and D. Rothe. 2014. "Securitizing 'Climate Refugees': The Futurology of Climate-Induced Migration.” Critical Studies on Security 2: 121-130.

Ballu, V., M. N. Bouin, P. Siméoni, W. C. Crawford, S. Calmant, J. M. Boré, T. Kanas, and B. Pelletier. 2012. "Comparing the Role of Absolute Sea-Level Rise and Vertical Tectonic Motions in Coastal Flooding, Torres Islands (Vanuatu)." Proceedings of the National Academy of Sciences 108: 13019-13022.

Baxter, J. A. and D. Armitage. 2012. "Place Identity and Climate Change Adaptation: A Synthesis and Framework for Understanding." WIREs Climate Change 3: 251-266.

Bettini, G. 2013. "Climate Barbarians at the Gate? A Critique of Apocalyptic Narratives on 'Climate Refugees'.”, Geoforum 45: 63-72.

Birks, M. and J. Mills. 2015. Grounded Theory: A Practical Guide. London: Sage.

Black, R., D. Kniveton, and K. Schmidt-Verkerk. 2013. "Migration and Climate Change: Toward an Integrated Assessment of Sensitivity." In Disentangling Migration and Climate Change edited by T. Faist and J. Schade, 29-53. London: Springer.

Böcker, A., K. Groenendijk, T. Havinga, and P. Minderhoud, eds. 1998. Regulation of Migration: International Experiences. Amsterdam: Het Spinhuis Publishers.

Brace, C. and H. Geoghegan. 2011. "Human Geographies of Climate: Landscape, Temporality and Lay Knowledges.” Progress in Human Geography 35: 284-302.

Brownlee, M. T. J., R. B. Powell, and J. C. Hallo. 2013. "A Review of the Foundational Processes that Influence Beliefs in Climate Change: Opportunities for Environmental Education Research.” Environmental Education Research 19: 1-20. 
Brzoska, M. and C. Fröhlich. 2016. "Climate Change, Migration and Violent Conflict: Vulnerabilities, Pathways and Adaptation Strategies." Migration and Development 5 (2): 190-210.

Burley, D., P. Jenkins, S. Laska, and T. Davis. 2007. "Place Attachment and Environmental Change in Coastal Louisiana." Organization and Environment 20: 347-366.

Charmaz, K. 2014. Constructing Grounded Theory: A Practical Guide through Qualitative Analysis, 2nd edn. Sage, London.

Curry, G. N., G. Koczberskia, and J. Connell. 2012. "Introduction: Enacting Modernity in the Pacific?" Australian Geographer 43: 115-125.

Doyle, J. 2013. Mediating Climate Change. Surrey: Ashgate.

Edwards, A. J., S. Clark, H. Zahir, A. Rajasuriya, A. Naseer, and J. Rubens. 2001. "Coral Bleaching and Mortality on Artificial and Natural Reefs in Maldives in 1998, Sea Surface Temperature Anomalies and Initial Recovery.” Marine Pollution Bulletin 42: $7-15$.

El-Hinnawi, E. 1985. Environmental Refugees. Nairobi: United Nations Environment Programme.

Fabian, J. 2014. Time and the Other: How Anthropology Makes Its Object. New York: Columbia University Press.

Farbotko, C. and H. Lazrus. 2012. "The First Climate Refugees? Contesting Global Narratives of Climate Change in Tuvalu." Global Environmental Change 22: 382-390.

Featherstone, D. 2013. "The Contested Politics of Climate Change and the Crisis of Neoliberalism." ACME 12: 44-64.

Felli, R. and N. Castree. 2012. "Neoliberalising Adaptation to Environmental Change: Foresight or Foreclosure?" Environment and Planning A 44: 1-4. 
Fincher, R., J. Barnett, S. Graham, and A. Hurlimann. 2014. "Time Stories: Making Sense of Futures in Anticipation of Sea-Level Rise." Geoforum 56: 201-210.

Foresight 2011. Migration and Global Environmental Change. London: Report for The Government Office for Science.

Gaillard, JC 2012. "The Climate Gap.” Climate and Development 4: 261-264.

Gemenne, F. 2011. "Why the Numbers Don't Add Up: A Review of Estimates and Predictions of People Displaced by Environmental Changes." Global Environmental Change 21S: 41-49.

Gemenne, F., P. Brücker, and D. Ionesco. 2013. The State of Environmental Migration 2013 A Review of 2012. Paris: IDDRI (Institute for Sustainable Development and International Relations).

Gerrard, M. B. and G. E. Wannier, eds. 2013. Threatened Island Nations: Legal Implications of Rising Seas and a Changing Climate. Cambridge: Cambridge University Press.

Ghina, F. 2003. "Sustainable Development in Small Island Developing States: The case of Maldives.” Environment, Development and Sustainability 5: 139-165.

Glantz, M. H., ed. 1999. Creeping Environmental Problems and Sustainable Development in the Aral Sea Basin. Cambridge: Cambridge University Press.

Glaser, B. G. and A. L. Strauss. 1967. The Discovery of Grounded Theory: Strategies for Qualitative Research. Chicago: Aldine.

Government of India 2011. Census of India. New Delhi: Government of India.

Government of India 2013. Press Notes of Poverty Estimates 2011-2012. New Delhi: Planning Commission, Government of India.

Government of Union Territory of Lakshadweep 2015. "Role of Women." Accessed 13 August 2015. http://lakshadweep.nic.in/KL_WomenRole.html 
Graham, S., J. Barnett, R. Fincher, A. Hurlimann, C. Mortreux, and E. Waters. 2013. "The Social Values at Risk from Sea-Level Rise.” Environmental Impact Assessment Review 41: 45-52.

Hartmann, B. 2010. "Rethinking Climate Refugees and Climate Conflict: Rhetoric, Reality and the Politics of Policy Discourse." Journal of International Development 22: 233246.

Hau'ofa, E. 1994. “Our sea of islands.” The Contemporary Pacific 6: 147-161.

Hayward, P. 2012. “Aquapelagos and Aquapelagic Assemblages.” 6: 1-11.

Held, D. 2016. "Climate Change, Migration and the Cosmopolitan Dilemma." Global Policy 7(2): $237-246$.

Hidalgo, M. C. 2013. "Operationalization of place attachment: A consensus proposal." Estudios de Psicología 34(23): 251-259.

Hirsch, E. 2015. “'It Won't Be Any Good to have Democracy if We Don’t Have a Country': Climate Change and the Politics of Synecdoche in the Maldives." Global Environmental Change 35: 190-198.

Huxley, A. 1962. Island. New York: Harper and Brothers.

IPCC 2014. Fifth Assessment Report. Geneva: IPCC (Intergovernmental Panel on Climate Change).

Kelman, I., R. Stojanov, S. Khan, O. A. Gila, B. Duží, and D. Vikhrov. 2015. "Islander Mobilities: Any Change from Climate Change?" International Journal of Global Warming 8: 584-602.

Kench, P. S., D. Thompson, M. R. Ford, H. Ogawa, and R. F. McLean. 2015. "Coral Islands Defy Sea-Level Rise Over the Past Century: Records from a Central Pacific Atoll.” Geology 43(6): 515-518. 
Klaiber, H. A. 2014. "Migration and Household Adaptation to Climate: A Review of Empirical Research.” Energy Economics 46: 539-547.

Kothari, U. 2014. "Climate Change and Migration: A Political Discourse of Resettlement in Maldives.” The Geographical Journal 180: 130-140.

LAPCC 2012. Lakshadweep Action Plan on Climate Change. Accessed 20 January 2015. http://www.moef.nic.in/sites/default/files/sapcc/Lakshadweep.pdf

McCright, A. M. and R. E. Dunlap. 2011. "The Politicization of Climate Change and Polarization in the American Public's Views of Global Warming, 2001-2010.” The Sociological Quarterly 52: 155-194.

McCubbin, S., B. Smit, and T. Pearce. 2015. "Where Does Climate Fit? Vulnerability to Climate Change in the Context of Multiple Stressors in Funafuti, Tuvalu." Global Environmental Change 30: 43-55.

McGranahan, D. A., D. Balk, and B. Anderson. 2007. "The Rising Tide: Assessing the Risks of Climate Change and Human Settlements in Low Elevation Coastal Zones." Environment \& Urbanization 19: 17-39.

McNamara, K. E. 2009. "Voices from the Margins: Pacific Ambassadors and the Geopolitics of Marginality at the United Nations." Asia Pacific Viewpoint 50: 1-12.

McNamara, K. E. and C. Gibson. 2009. “"We Do Not Want to Leave Our Land': Pacific Ambassadors at the United Nations Resist the Category of 'Climate Refugees'." Geoforum 40: 475-483.

Melillo, J. M., T. C. Richmond, and G. W. Yohe, eds. 2014. Climate Change Impacts in the United States: The Third National Climate Assessment. Washington, DC: U.S. Global Change Research Program.

Moser, S. C. and L. Dilling. 2004. "Making Climate Hot: Communicating the Urgency and Challenge of Global Climate Change." Environment 46: 32-46. 
Munch, P. A. 1964. "Culture and Superculture in a Displaced Community: Tristan da Cunha." Ethnology 3: 369-376.

Myers, N. 1997. “Environmental Refugees.” Population and Environment 19: 167-182.

Nicholson, C. 2014. "Climate Change and the Politics of Causal Reasoning: The Case of Climate Change and Migration." The Geographical Journal 180: 151-160.

Novaczek, I., J. MacFadyen, D. Bardati, and K. MacEachern. 2011. Social and Cultural Values Mapping as a Decision-Support Tool for Climate Change Adaptation. Charlottetown: The Institute of Island Studies, University of Prince Edward Island.

Obokata, R., L. Veronis, and R. McLeman. 2014. "Empirical Research on International Environmental Migration: A Systematic Review." Population and Environment 36: 111-135.

Palutikof, J., S. L. Boulter, A. J. Ash, M. S. Smith, M. Parry, N. Waschka, and D. Guitart. 2013. Climate Adaptation Futures. Chichester: Wiley-Blackwell.

Pandolfi, J. M. 2015. "Incorporating Uncertainty in Predicting the Future Response of Coral Reefs to Climate Change." Annual Review of Ecology, Evolution, and Systematics 46: 281-303.

Paton, D. 2001. "Responding to Hazard Effects: Promoting Resilience and Adjustment Adoption." Australian Journal of Emergency Management 16: 47-52.

Paton, K. and P. Fairbairn-Dunlop. 2010. "Listening to Local Voices: Tuvaluans Respond to Climate Change.” Local Environment 15: 687-698.

Perch-Nielsen, S. L., M.B. Bättig, and D. Imboden. 2008. "Exploring the Link Between Climate Change and Migration." Climatic Change 91: 375-393.

Petersen, W. 1958. “A General Typology of Migration.” American Sociological Review 2: 256-266. 
Rollero, C. and N. De Piccoli. 2010. "Place attachment, identification and environment perception: An empirical study." Journal of Environmental Psychology 30(2): 198-205.

Piguet, E. 2012. 'From 'Primitive Migration' to 'Climate Refugees': The Curious Fate of the Natural Environment in Migration Studies.” Annals of the Association of American Geographers 103: 148-162.

Pirrwitz, A. and K. Honnef. 2010. Photographie. Sieben tempophile Etüden. Berlin/Heidelberg: Verlag.

Portes, A. and J. Dewind, eds. 2007. Rethinking Migration: New Theoretical and Empirical Perspectives. Oxford: Berghahn Books.

Rankey, E. C. 2011. "Nature and Stability of Atoll Island Shorelines: Gilbert Island Chain, Kiribati, Equatorial Pacific.”Sedimentology 58: 1831-1859.

Riyaz, M. and K.-H. Park. 2010. “'Safer Island Concept' Developed After The 2004 Indian Ocean Tsunami: A Case Study Of Maldives.” Journal of Earthquake and Tsunami 4: 135-143.

Roberts, E. and S. Andrei. 2016. "The Rising Tide: Migration as a Response to Loss and Damage from Sea Level Rise in Vulnerable Communities." International Journal of Global Warming 8: 258-273.

Roca, Z. and de Nazaré Oliveira-Roca, M. 2007. "Affirmation of territorial identity: A development policy issue.” Land Use Policy 24(2): 434-442.

Ruddell, D., S. L. Harlan, S. Grossman-Clarke, and G. Chowell. 2012. "Scales of Perception: Public Awareness of Regional and Neighborhood Climates." Climatic Change 111: 581-607.

Rudiak-Gould, P. 2013. Climate Change and Tradition in a Small Island State: The Rising Tide. Abingdon: Routledge. 
Shen, S. and F. Gemenne. 2011. "Contrasted Views on Environmental Change and Migration: the Case of Tuvaluan Migration to New Zealand.” International Migration 49: e224-e242.

Slawinski, N. and P. Bansal. 2012. "A Matter of Time: The Temporal Perspectives of Organizational Responses to Climate Change.” Organization Studies 33: 1537-1563.

Sovacool, B. K. 2012a. "Expert Views of Climate Change Adaptation in the Maldives." Climatic Change 114: 295-300.

Sovacool, B. K. 2012b. "Perceptions of Climate Change Risks and Resilient Island Planning in the Maldives." Mitigation and Adaptation Strategies for Global Change 17: 731752.

Stal, M. and K. Warner. 2009. The Way Forward: Researching the Environment and Migration Nexus. Bonn: UNU EHS (United Nations University Institute for Environment and Human Security).

Steel, T. 1975. The Life and Death of St. Kilda. New York: Fontana.

Tacoli, C. 2009. "Crisis or Adaptation? Migration and Climate Change in a Context of High Mobility.” Environment \& Urbanization 21: 513-525.

Taylor, M. 2014. The Political Ecology of Climate Change Adaptation: Livelihoods, Agrarian Change and the Conflicts of Development. London: Routledge.

Trask, H.-K. 1991. "Natives and Anthropologists: The Colonial Struggle." The Contemporary Pacific 3: 159-166.

Tuan, Y.-F. 1974. Topophilia: A Study of Environmental Perception, Attitudes, and Values. New York: Columbia University Press.

Upadhyay, H., I. Kelman, G. J. Lingaraj, A. Mishra, C. M. Shreve, and R. Stojanov. 2015. “Conceptualizing and Contextualizing Research and Policy for Links between Climate 
Change and Migration." International Journal of Climate Change Strategies and Management 7: 394-417.

Veron, J. E. N., O. Hoegh-Guldberg, T. M. Lenton, J. M. Lough, D. O. Obura, P. PearceKelly, C. R. C. Sheppard, M. Spalding, M. G. Stafford-Smith, and A. D. Rogers. 2009. "The Coral Reef Crisis: The Critical Importance of $<350$ ppm $\mathrm{CO}_{2}$. " Marine Pollution Bulletin 58: 1428-1436.

Webb, A. P. and P. S. Kench. 2010. “The Dynamic Response of Reef Islands to Sea-Level Rise: Evidence from Multi-Decadal Analysis of Island Change in the Central Pacific.” Global and Planetary Change 72: 234-246.

Wilkinson, C. 2008. Status of coral reefs of the world: 2008. Townsville: Global Coral Reef Monitoring Network and Reef and Rainforest Research Centre.

Willox, A. C., S. L. Harper, J. D. Ford, K. Landman, K. Houle, and V. L. Edge. 2012. "From this Place and of this Place: Climate Change, Sense of Place, and Health in Nunatsiavut, Canada." Social Science \& Medicine 75: 538-547.

Withagen, C. 2014. "The Climate Change, Migration and Conflict Nexus." Environment and Development Economics 19: 324-327.

Wolpert, J. 1966. "Migration as an Adjustment to Environmental Stress." Journal of Social Issue 22(4): 92-102.

Wright, H., S. Vermeulen, G. Lagand, M. Olupot, E. Ampaire, E., and M. L. Jat. 2014. "Farmers, Food and Climate Change: Ensuring Community-Based Adaptation is Mainstreamed into Agricultural Programmes." Climate and Development 6: 318-328.

Yamamoto, L. and M. Esteban. 2014. Atoll Island States and International Law: Climate Change Displacement and Sovereignty. Berlin: Springer. 